\title{
La autonomía individual bajo la tutela del binomio médico-jurídico: hacia una conceptualización histórico-relacional ${ }^{1}$
}

Individual autonomy under the tutelage of the medical-legal binomial: towards a historical-relational conceptualization

Rubén Alejandro Nilo Pérez

Escuela de Psicología, Facultad de Ciencias Sociales y Comunicaciones, Universidad Santo Tomás, Chile

En el artículo titulado "La autonomía individual bajo la tutela del binomio médico-jurídico: hacia una conceptualización histórico-relacional", del autor Rubén Alejandro Nilo Pérez, publicado en el volumen 30, nro.2 de 2020, se señala en pie de página inicial que este artículo se ha desarrollado en el marco del proyecto FONDECYT № 1180338 y debiera decir, además, que es parte del trabajo de tesis del programa de Doctorado en Estudios Americanos de la Universidad de Santiago de Chile. 